\title{
Demographic Variables Influencing Perceived Effectiveness of Career Guidance during Life Orientation
}

\author{
* $P$ Jonck \\ PhD Psychology; Honours Industrial Psychology,
Deputy Director: Research and Policy Development, Department of Community Safety, Gauteng Provincial Government \\ petrojonck@hotmail.com / Petronella.jonck@yahoo.com
}

EH Swanepoel

Office of the Dean, Psychology of Education, University of the Free State swanepoeleh@ufs.ac.za/ ebenswan@gmail.com

\section{Doi:10.5901/mjss.2015.v6n3s2p297}

\begin{abstract}
Career guidance at secondary schooling level is pivotal in preparing learners for the current globalized workforce and is also a core pillar of Life Orientation. The aim of this study was twofold subsuming determining the effectiveness of career guidance as perceived by 430 Grade 10 learners in the Mangaung area and to determine the demographic variables that influenced said perceived effectiveness. By means of descriptive statistics, personal confidence, personality inventories, knowledge of career plan, overall subject satisfaction and service delivery were examined. Service delivery was further disaggregated to determine the effectiveness of subcomponents. A T-test and MANOVA were performed to investigate the demographic variables. Findings reflect a deficit in the domains of personal confidence and service delivery, with a higher perceived effectiveness pertaining to knowledge and subject satisfaction. Gender, age, home language and type of school statistically significantly influenced perceived effectiveness. Type of school was the most important determinant of perceived effectiveness of career guidance received. Within the South African context these results suggest a lingering influence of segregation as not everyone is privy to effective career guidance hampering economic development and keeping a large part of the country in poverty. It is suggested that the results of the study be used as an impetus to stimulate further study focusing on specific types of schools.
\end{abstract}

Keywords: Career guidance; Life Orientation; Service delivery; Quantitative analysis; Social Cognitive Career Development Theory.

\section{Introduction}

The post-apartheid landscape in South Africa saw the implementation of a new curriculum as a means to restoring inequality as such to accommodate democratic values and the principles of social justice (Adewumi, 2012). Simultaneously, the dynamic workings of globalization and the technologically driven vocational environment further complicated the process of not only incorporating a curriculum to address these disparities, but also the process of career planning for prospective graduates as a whole (Maree \& Beck, 2004; Stead \& Watson, 2010). As a means to promote the successful transition from school to the employment sector and address the aforementioned influences on career decision-making, career education and guidance have become cornerstone measures in holistically preparing learners for the demands of the contemporary workforce (Department of Education, 2011; Prinslo0, 2007).

In light of the above, South African school policy saw the implementation of Life Orientation at curriculum level as compulsory method to provide psychological, emotional and physical growth towards the aim of becoming democratic citizens within society (Jacobs, 2011). A core pillar in Life Orientation is career guidance, a component that addresses content areas aimed at fostering the learners' ability to make informed choices about future career planning (Chiresche, 2006). It is during grade 9 that learners are expected to make subject selection that will ultimately lead to further studies and envisioned occupational choices post-grade 12. In order to make relevant subject selection and engage learners for the remainder of their Future Education and Training Phase (Grade 10 to 12), it is critical that grade 9 learners are equipped with the knowledge and skillsets to choose the correct subjects (Van de Venter, 2006).

Coetzee and Esterhuizen (2010) however question the sustainability of career guidance as based on current policies, especially in relation to providing learners with the skillsets to adapt optimally within the current vocational landscape. Various research studies have indicated that the effectiveness of career guidance given to learners is 
questionable (Jacobs, 2011:213; Christiaans, 2005: 133). Rooth (2005), aligned with Magano (2011), argued that teachers are often inadequately equipped to teach career guidance programmes effectively. Teachers are further limited in that they are not qualified to administer and interpret psychological measures of aptitude or personality inventories as such tests require qualified professionals (Health Professions Council of South Africa, 2010). Consequently, limiting the process of a holistic approach to career guidance. Especially in light of the fact that Dabula and Makura (2013) found in a South African sample that lack of self-knowledge hindered learners' ability to make informed career choices.

Van de Venter (2006) found in a study of grade 9 learners' experiences of career guidance that learners are not fully informed and guided to make subject choices, but particulars as to the evaluation are deficient, especially underscoring service delivery. In addition, in accordance to national and international trends most of the studies exploring the effectiveness of career guidance are qualitative in nature providing contextual information (Mareer, 2007; Maree \& Molepo, 2006; McMahon \& Watson, 2009) but limited with reference to the generalizability of the findings. Consequently, the current investigation evaluated grade 10 learners' perception of the career guidance received as part of Life Orientation quantitatively. The primary aim of the study elaborate further on the before mentioned by determining the demographic variables that influence perceived effectiveness of career guidance received. As the study is focussed on learners that have entered the Further Education and Training Phase (Grade 10), it provides valuable information to gain a deeper understanding as to which factors mediated perceived effectiveness of Life Orientation received prior to subject selection.

\section{Theoretical Framework}

This study was underpinned by the Social Cognitive Career Development Theory (SCCT) as a basis to understand perceived effectiveness of career guidance received during Life Orientation. The applicability of the SCCT as theoretical framework to elucidate career, subject choices and perception of career guidance has been verified nationally (Dabula \& Makura, 2013; Jonck, 2014) and internationally (Tang, Pan \& Newmeyer, 2008; Turner \& Lapan, 2002). The SCCT provides a comprehensive framework within which to understand how career interest, choices and performance are grounded in self-efficacy (Leung, 2008) preceded by learning experiences (Jonck, 2014). Mills (2009) defines self-efficacy as an individual's judgments of their abilities to pursue and attain set goals. Past experiences and contextual factors (i.e. quality of educational experiences) are mediators in developing career interests and choices (Lindley, 2005). Thus, quality of learning experiences statistically significantly influence self-efficacy, which then have bearing on career interest and choices (Jonck, 2014; Tang et al., 2008; Turner \& Lapan, 2002). The SCCT forms a valuable framework to understand how South Africa's unequal distribution of resources and past discrepancies of educational quality influence career planning (Coetzee \& Esterhuizen, 2010).

\section{Research Methodology}

This study investigated learners located in the Mangaung area of the Free State province. For the purpose of this study only secondary schools were randomly sampled, with a total of seven public schools forming part of the final data analysis. At the time of the study a learner population of approximately 640000 was reflected in the province (Department of Basic Education, 2012). A total of 430 respondents formed part of the final sample, with 155 being male and 275 female. As the study was conducted on Grade 10 learners, the majority were between the ages of 15 and 17 , with 24 older than 17. Only 30 participants indicated English as their first language, with a dominant amount of learners indicating Afrikaans as mother tongue ( $\mathrm{N}=235)$ and 165 specifying an indigenous language. The majority of participants further indicated they belong to the middle socio-economic strata, although it should be taken into consideration that this perception is based on a self-report measure and thus open for interpretation.

\subsection{Research design and procedure}

A cross-sectional descriptive empirical investigation was conducted using a survey research method. The research design can be classified as cross-sectional since data collection took place at a specific point in time without repeat measures. The study can be seen as descriptive since the main objective was to describe a population phenomenon (Salkind, 2011). A characteristic of the research design is that it was an Ex Post Facto design referring to the fact that no experimental intervention took place and respondents belonged to the various demographic variables prior to data collection. A two-pronged procedure was used in that firstly a list of all the secondary schools in the central Free State region, Mangaung area, was obtained. From this list a random sample was drawn by including every fifth school. Not all 
the schools that were selected opted to participate in the research study. The final sample consisted out of 7 secondary schools. Secondly, after gate-keepers consent was obtained the questionnaires were handed out at participating schools indicative of convenient sampling. The final sample consisted out of 430 respondents which can be seen as representative of the population in accordance with Leedy and Ormrod (2001) who suggest that when a population exceed 5000 a sample size of 400 can be deemed as representative.

\subsection{Data collection instrument and analysis}

A closed questionnaire, based on a literature review, was compiled to measure the effectiveness of career guidance at secondary school level. The self-reporting instrument covering five categories consisted out of 25 statements to be rated on a four point Likert-type scale by respondents as "Always", "Frequently", "Sometimes" or "Never". The categories covered included service delivery (e.g. My life orientation teacher teaches us study methods to study more effectively), personal confidence (e.g. I am confident that I will be able to choose a study field from a list of potential study fields that I am considering), Completion of personality inventories (e.g. I have done a personality versus job questionnaire), Overall knowledge of career path (e.g. I know what I want to do after school) and Overall satisfaction with subject choices (e.g. I have chosen the correct subjects). Questionnaire development took place in accordance with the theoretical framework and was based on the SCCT (Jonck, 2014).

Pilot study results indicated a Cronbach Alpha reliability coefficient of 0.86 and the main study's reliability was 0.85 . Statistical analysis was carried out by means of measures for central tendency including median, mean and standard deviation. The main aim of the research reported on were achieved by means of inferential statistical analysis subsuming T-test for Independent Groups for gender ascribed to the fact that gender only consist out of two levels and Multivariate Analysis of Variance (MANOVA) since more than one dependent variable were included in the analysis as different categories covered by the measuring instrument.

\subsection{Ethical consideration}

As the study was conducted on minors, consent had to be obtained at various levels. Ethical clearance was obtained at Provincial level to conduct the research in schools, as well as institutional level where the researchers were based. Principals were approached and accepted or declined to partake in the study, while those who accepted distributed the consent forms to the learners' legal guardians for parental consent. No deception took place and all stakeholders were fully informed about the aims and scope of the study, and were ensured of anonymity, confidentiality and that no psychological and physical harm could be incurred during the process of participation.

\section{Findings of the Study}

The objectives of the research reported on in this paper were to determine the effectiveness of the component, career guidance, which forms part of the subject Life Orientation empirically using a quantitative measuring instrument. In addition, to determine the demographic variables that influence the aforementioned evaluation. To this end the demographic data were subjected to analysis using measures for central tendency which are reported on in Table 1 . In each case the median represent the 50\% mark after which the median and mean are compared with each other to determine whether the evaluation is positive conversely negative.

Table 1: Measures for central tendency

\begin{tabular}{|l|c|c|c|c|c|}
\hline Variable & Lower quartile & Upper quartile & Median & $\overline{\bar{x}}$ & St \\
\hline Services provided & 1 & 4 & 2.5 & 2.5 & 0.549 \\
\hline Personal confidence & 1 & 4 & 1.8 & 1.82 & 0.474 \\
\hline Personality inventory & 1 & 4 & 2 & 2.19 & 0.858 \\
\hline Overall knowledge of career plan & 1 & 4 & 1 & 1.7 & 0.570 \\
\hline Overall satisfaction with subject choices & 1 & 4 & 1 & 1.61 & 0.718 \\
\hline
\end{tabular}

As seen in Table 1 overall respondents were reasonable satisfied with the component career guidance as part of the subject Life Orientation. Services provided was the variable that received the worst evaluation followed by the completion 
of personality inventories. Personal confidence followed in the third place. Overall satisfaction with subject choices and knowledge of career path received the most favourable evaluation. Given the results discussed in Table 1 the specific services respondents evaluated were scrutinised further.

Table 2: Mean procedures for services provided

\begin{tabular}{|l|c|c|c|c|c|}
\hline Variable & Lower quartile & Upper quartile & Median & $\bar{\nabla}$ & St \\
\hline Provision of career guidance & 1 & 3 & 2 & 2.26 & 0.947 \\
\hline Individual attention & 1 & 3 & 3 & 3.16 & 0.982 \\
\hline Discussion with guardian & 1 & 4 & 4 & 3.59 & 0.752 \\
\hline Study methods & 1 & 3 & 2 & 2.05 & 0.974 \\
\hline Time management & 1 & 3 & 2 & 1.95 & 1.016 \\
\hline Motivation & 1 & 2 & 1 & 1.64 & 0.852 \\
\hline Stress management & 1 & 3 & 2 & 2.28 & 1.005 \\
\hline Job searching instructions & 3 & 4 & 3 & 3.12 & 0.919 \\
\hline Intrapersonal knowledge & 1 & 3 & 2 & 1.96 & 0.940 \\
\hline Access to job information & 2 & 4 & 3 & 2.81 & 1.045 \\
\hline Access to higher education information & 2 & 4 & 3 & 2.67 & 1.10 \\
\hline Access to electronic aids & 1 & 4 & 3 & 2.52 & 1.232 \\
\hline
\end{tabular}

According to Table 2 discussion with legal guardians seems to almost never take place. Similarly individual attention is lacking and instruction on how to look and apply for a job tends to be on a continuum between sometimes and never although the latter might take place at a later stage. There was a further low ranking of access to higher education information and electronic aids. The most positive evaluations of career guidance pertaining to service delivery seems to be related to emotional support including motivation, intrapersonal development and time management. Emphasis was also placed on study methods during service delivery.

To investigate the primary aim of the study which was to determine the demographic variables that statistically significantly influenced grade 10 learners' evaluation of career guidance provided inferential statistical analysis were performed. Ascribed to the fact that gender only consisted out of two categories a T-Test with equal variance assumed was performed and illustrated in Table 3 followed by the MANOVA results for the remaining demographic variables (Table 4).

Table 3: T-test results for gender as independent variable with various aspects of career guidance as dependent variables

\begin{tabular}{|l|c|c|c|}
\hline Dependent variables & $\mathbf{t}$ & $\mathbf{d f}$ & $\mathbf{p}$ \\
\hline Service delivery & 2.859 & 427 & $0.004^{\star \star}$ \\
\hline Personal confidence & 1.054 & 427 & 0.292 \\
\hline Completion of personality inventories & 0.955 & 423 & 0.340 \\
\hline Knowledge of career path & -0.832 & 425 & 0.406 \\
\hline Subject satisfaction & -0.587 & 4.26 & 0.557 \\
\hline
\end{tabular}

${ }^{\star} p \leq 0.05 ;{ }^{* \star} p \leq 0.01 ;{ }^{* \star \star} p \leq 0.001$

As can be seen from Table 3 above the only statistical significant influence gender had on aspects related to career guidance was in reference with service delivery on the 99th percentile. An inspection of the mean scores indicated that the male respondents reported slightly lower levels of perceived service delivery satisfaction $(x=2.60 ; S D=0.542)$ than the female respondents $\left(x^{-}=2.44 ; S D=0.546\right)$. Please take note that the scores ranged from 1 being positive and 4 being negative. 
Table 4: MANOVA test results for various demographic variables and aspects related to career guidance

\begin{tabular}{|l|l|c|c|c|}
\hline Independent variables & Dependent variable & $\mathbf{f}$ & $\mathbf{d f}$ & $\mathbf{p}$ \\
\hline \multirow{4}{*}{ Age } & Service delivery & 8.182 & 2 & $0.000^{\star \star \star}$ \\
\cline { 2 - 5 } & Personal confidence & 1.281 & 2 & 0.279 \\
\cline { 2 - 5 } & Completion of personality inventories & 0.478 & 2 & 0.620 \\
\cline { 2 - 5 } & Knowledge of career path & 2.819 & 2 & 0.061 \\
\cline { 2 - 5 } & Subject satisfaction & 1.742 & 2 & 0.177 \\
\hline \multirow{5}{*}{ Home language } & Service delivery & 1.269 & 2 & 0.282 \\
\cline { 2 - 5 } & Personal confidence & 3.355 & 2 & $0.036^{\star}$ \\
\cline { 2 - 5 } & Completion of personality inventories & 6.460 & 2 & $0.002^{\star \star}$ \\
\cline { 2 - 5 } & Knowledge of career path & 16.882 & 2 & $0.000^{\star \star \star}$ \\
\cline { 2 - 5 } & Subject satisfaction & 3.910 & 2 & $0.021^{\star}$ \\
\hline \multirow{5}{*}{ Socio-economic status } & Service delivery & 1.014 & 2 & 0.364 \\
\cline { 2 - 5 } & Personal confidence & 2.921 & 2 & 0.055 \\
\cline { 2 - 5 } & Completion of personality inventories & 0.009 & 2 & 0.991 \\
\cline { 2 - 5 } & Knowledge of career path & 0.851 & 2 & 0.428 \\
\cline { 2 - 5 } & Subject satisfaction & 1.466 & 2 & 0.232 \\
\hline Type of school & Service delivery & 39.334 & 2 & $0.000^{\star \star \star}$ \\
\cline { 2 - 5 } & Personal confidence & 10.297 & 2 & $0.000^{\star \star \star}$ \\
\cline { 2 - 5 } & Completion of personality inventories & 7.281 & 2 & $0.001^{\star \star \star}$ \\
\cline { 2 - 5 } & Knowledge of career path & 29.310 & 2 & $0.000^{\star \star \star}$ \\
\cline { 2 - 5 } & Subject satisfaction & 2.881 & 2 & 0.057 \\
\hline
\end{tabular}

${ }^{*} p \leq 0.05 ;{ }^{* \star} p \leq 0.01 ;$ *** $p \leq 0.001$

Statistical analysis indicated there were a statistically significant difference between the age groups on the combined dependant variables (Wilks' Lambda $F=2.395 ; p=0.008$; partial eta squared $=0.028$ ). When the results for the dependent variables were considered separately as can be seen from Table 4 the only difference to reach statistical significance was services provided. An inspection of the mean scores indicated that the 15 to 17 years age group reported slightly lower levels of perceived service delivery satisfaction $\left(x^{-}=2.53 ; S D=0.541\right)$ than the 12 to 14 age group $\left(x^{-}=2.26 ; S D=0.573\right)$, followed by the older than 17 years of age group $\left(x^{-}=2.12 ; S D=0.537\right)$ which were the most positive in relation to the other age groups. A relative small variance in the dependent variables could be explained by age (2.8\%). Home language also indicated a statistically significant difference on the combined dependant variables (Wilks' Lambda $F=4.322 ; p=0.000$; partial eta squared $=0.049$ ). When considering the results for the dependant variables separately personal confidence, completion of personality inventories, overall knowledge of career path and overall satisfaction with subject choices reached statistical significance. An inspection of the mean scores indicated that with reference to personal confidence Afrikaans speaking respondents reported slightly lower levels of perceived personal confidence $\left(x^{-}=1.87 ; S D=0.515\right)$ than English speaking respondents $\left(x^{-}=1.81 ; S D=0.390\right)$. In the last instance those who spoke an Indigenous language had a mean score of 1.75 and a standard deviation of 0.420 . With reference to the completion of personality inventories the Afrikaans speaking respondents once again had lower levels $(x$ $=2.31 ; \mathrm{SD}=0.888)$ as appose to those who spoke an Indigenous language $\left(\mathrm{x}^{-}=2.06 ; \mathrm{SD}=0.760\right)$ and English $\left(\mathrm{x}^{-}=\right.$ $1.87 ; \mathrm{SD}=0.860)$ as their mother tongue. With reference to overall knowledge of career path the same trend persisted with Afrikaans speaking respondents reporting a slightly lower mean $\left(x^{-}=1.92 ; \mathrm{SD}=0.946\right)$ than the English speaking respondents $\left(x^{-}=1.53 ; S D=0.730\right)$ and lastly those who spoke and Indigenous language $\left(x^{-}=1.43 ; S D=0.641\right)$ were the most positive. Lastly, with reference to overall subject satisfaction the English speaking respondents reported the lowest levels of satisfaction with a mean of $1.70(S D=0.702)$, followed by Afrikaans speaking respondents with a mean of $1.67(\mathrm{SD}=0.715)$ and those who spoke an Indigenous language with a mean of $1.48(\mathrm{SD}=0.692)$. As indicated by the partial eta squared $4.9 \%$ in the variance of the dependant variables could be explained by home language. With reference to socio-economic status no statistical significance was observed and only $1.2 \%$ of the variance in the dependant variables could be explained by the independent variable socio-economic status.

Type of school was the independent variable that had the biggest influence on the dependant variables. Results indicated that type of school had a statistical significant influence on the combined dependant variables with a Wilks' Lambda $F$ value of 13.843 , a significance value of $p=0.000$ and a partial eta squared of 0.142 . Thus $14.2 \%$ of the variance in the dependant variables could be attributed to type of school. When consideration was given to the dependent variable separately statistical significant differences were observed for services provided, personal confidence, 
completion of personality inventories, and overall knowledge of career path. An inspection of the mean scores indicated that the predominantly white schools reported slightly lower levels of satisfaction with services provided $\left(x^{-}=2.67 ; \mathrm{SD}=\right.$ $0.552)$ than the predominantly black schools $\left(x^{-}=2.50 ; S D=0.475\right)$. The predominantly coloured school reported the highest levels of overall subject satisfaction with a mean score of $1.97(S D=0.474)$. With reference to personal confidence the predominantly coloured schools had the highest mean score $\left(x^{-}=1.60\right.$; $\left.S D=0.481\right)$, followed by the predominantly black schools $\left(x^{-}=1.80 ; S D=0.452\right)$ and in the last instance the predominantly white schools $\left(x^{-}=1.92\right.$; $S D=0.477)$. The mean scores for the completion of personality inventories followed mostly the same pattern with predominantly black schools indicating the most positive mean score $\left(x^{-}=2.03\right.$; $\left.S D=0.809\right)$ followed by the predominantly coloured schools $\left(x^{-}=2.24 ; S D=0.860\right)$ and lastly the predominantly white schools with the most negative mean score of $2.36(S D=0.865)$. With reference to overall knowledge of career path this trend persisted once again with predominantly coloured schools have a mean of $1.38(S D=0.707)$, followed by predominantly black schools with a mean of $1.48(S D=0.703)$ and lastly predominantly white schools with a mean of 2.08 and a standard deviation of 0.964 .

\section{Discussion of Results}

In order to determine the effectiveness of a career guidance programme it is paramount to take cognisance of the aims and objectives as well as the attainability thereof. The National Curriculum Statement specify that the aim of career guidance, or the world of work as it is termed, is to assist learners to make informed subject choices and to participate in the economy (Department of Basic Education, 2011). Despite this the required subjects needed to gain access to higher education institutions does not seem to be discussed or mentioned specifically. The needs of the labour market are not emphasised which might lead to pursuing careers where the demand is less acute as well as disciplinary fields that do not directly lead to a specific profession. Guidelines on how to address these topics in the classroom are not mentioned and are left to the discretion of teachers with no formal career guidance training except for workshop attendance.

A prominent finding of the study is based on the overall high satisfaction with subject choices as reflected through Table 1 (Mean = 1.61). This internal locus of perceived satisfaction is further reiterated through the two intrinsic categories of overall knowledge of career path (Mean $=1.7$ ) and personal confidence (Mean $=1.82)$. Extrinsic motivators that scored low were personality inventories (Mean $=2.19$ ) and services provided (Mean $=2.5$ ). From these results it can be deduced that internal-oriented dependent variables influence perception of career guidance satisfaction more than the external-oriented dependent variables.

Services provided was the aspect of career guidance that received the most negative evaluation (Mean $=2.5$ ). Further probing indicated that discussion with legal guardians tend to be lacking (Mean $=3.59$ ) along with individual attention (Mean = 3.16). It would appear that subject and career choices are made solely on the basis of class room instruction. The attachment relationship with parents has been recognised as an important factor in learners' career development (Turner \& Lapan, 2002). Research has established correlations between learners' perception of parental security and career exploration, decidedness and commitment to career choices (Germeijs \& Verschueren, 2009). Magano (2011) argues that the role of township Life Orientation teachers as a parental figure becomes especially important, as many learners in this context is subject to child-headed families. Making subject and career decisions are stressful because it is a complex process and the presence and support of learners' legal guardians and/or parents would facilitate this process.

As part of services provided, the second lowest rating were given to individual discussions and support (Mean = 3.16). Research by Mittendorf, den Brok and Beijaard (2010) indicated that the provision of individual guidance is deemed an essential element of career guidance since learners often experience difficulty reflecting on their own learning processes or to construct meaning about themselves and future career choices. This aligns with Magano (2011) who recommended that Life Orientation teachers must be allocated enough time to fulfil one-on-one consultation sessions with learners. It is aligned with the Social Cognitive Career Development Theory that social support underscores a pivotal role in forming career interests and choices, as the positive connection between such support and self-efficacy has been documented (Leung, 2008).

Bholanath (2007) made mention of three conditions for successful vocational decision-making, namely possessing alternative options, motivation, and freedom to choose. As Life Orientation aims to prepare learners for their respective roles in the world of work (Department of Basic Education, 2011), these three conditions are viable to consider within the interpretation of the results. Motivation is indicated in table 2 with a mean of 1.64 is indicated as a very positive source to perceptions of service delivery. However, further probing reveals that a deficiency in satisfaction occurred in the areas of access to job information and higher education information in addition to access to electronic aids. This in turn renders a lower rating for service delivery satisfaction and also hinders freedom of choice and the availability of alternative options. 
It would be consistent with the results to maintain that personal confidence and overall knowledge of career path acts as mediating agents to increase perceived career guidance satisfaction.

These results are consistent with the findings of Van de Venter (2006) that learners are not always fully equipped to optimally make subject choices. While the study found a high evaluation of subject satisfaction, factors that are critical to sustainability of career planning is in the deficit such as personal confidence and support. Aligned with the Social Cognitive Career Development Theory, future career decisions will be hindered. As such this study provides a platform to gain deeper understanding as to factors that currently inhibit the self-efficacy of learners.

Demographic variables that influenced the before mentioned findings subsumed gender, age, home language and type of school. The most significant finding relates to self-efficacy or personal confidence which were statistically significantly influenced by home language and type of school. In accordance with the SCCT self-efficacy is pivotal in career decision-making and development (Leung, 2008).

\section{Limitations}

A quantitative research study might be limited taking into consideration specific concerns of a heterogeneous population presenting with various complex risk factors such as presented within the South African context. Perry, Dauwalder and Bonnet (2009) noted that there appears to be an unavoidable tension between quantitative and qualitative program evaluation. It was suggested that meta-analysis would aid overall effectiveness of career interventions. Meta-analysis involves identifying commonalities in various empirical studies which is currently lacking due to the qualitative nature of most research done on the effectiveness of career guidance programs. Supporting qualitative research should be carried out to validate quantitative findings. Secondly, the research study was carried out within a specific region and can only be generalised to that region. It is therefore recommended that the study by carried out nationally to determine the effectiveness of the career guidance as part of Life Orientation.

\section{Conclusions and Recommendations}

The aim of this study was to determine the effectiveness of career guidance within the subject Life Orientation as perceived by secondary schooling learner's post-subject selection. Results reflect an overall satisfaction and effective evaluation. It was found that knowledge of career paths and personal confidence were dominant factors that influenced a positive evaluation, while services provided and personality inventories reflect the domains that hindered perceived satisfaction significantly. While knowledge of career path and subject selection satisfaction received high ratings, the domain of confidence and service delivery received lower ratings. As Life Orientation aims to stimulate learners' emotionally, physically, and psychologically, a deficit is found within the domain of heightening personal-confidence related to career guidance received. This evaluation is informed by an emphasis on content, and as stated earlier, is highly underscored by classroom instruction with little one-on-one consultation.

In order to promote self-agency and pro-activity for future career planning, teachers should be provided with the chance to engage learner's on a personal level in order to provide a contextual approach that is relevant to the learners' unique backgrounds and experiences. A greater emphasis during classroom practice based on methods of searching for job information, means of accessing further education and training, and searching for jobs are also needed. During Grade 9, only 11 hours are allocated towards career guidance (Department of Basic Education, 2011), while this is often further hindered by schools where resources are inadequate (as reflected through the low ratings of access to electronic material). It is however critical to draw on the multi-stakeholder dimension of Life Orientation, and that the teacher is merely one agent within the process of career guidance. Providing the chance to speak to parents and guardians will provide a platform where classroom practice and community engagement becomes unison, and we thus recommend that parents are engaged in the process of career guidance, and not isolating career guidance to the classroom environment.

\section{References}

Dewumi, T. M. 2012. An investigation into the implementation of the life orientation curriculum in selected Fort Beaufort district high schools (Doctoral dissertation, University of Fort Hare), Eastern Cape.

Bholanath, S. 2007. Effects of career guidance on grade 9 learner's readiness to make career choices. (Masters Dissertation), University of Zululand.

Chireshe, R. 2012. Career Guidance and Counselling Provisions at a South African University: Career Advisors' Reflections. Anthropologist, 14(4), 305 - 310. http://www.krepublishers.com/02-Journals/T-Anth/Anth-00-0-000-000-1999-Web/Anth-00-0- 
000-000-1999-1-Cover.htm

Christaains, D.J. 2006. Empowering teachers to implement the Life Orientation learning area in the Senior Phase of the General Education and Training Band. (Masters Dissertation), University of Stellenbosch, Stellenbosch.

Coetzee, M., \& Esterhuizen, K. 2010. Psychological career resources and coping resources of the young unemployed African graduate: An exploratory study. South African Journal of Industrial Psychology, 36(1), 1 - 9. 10.4102/sajip.v36i1.868

Dabula, P., \& Makura, A.H. 2013. High school student's perception of career guidance and development programmes for University access. International Journal for Educational Studies, 5(2), 89-97.

Department of Basic Education. 2012. Education statistics in South Africa 2010. Pretoria: Government Printing Works.

Department of Basic Education. 2011. Curriculum and Assessment Policy Statement Grades 7-9: Life Orientation. Government Printing Work, South Africa, Pretoria.

Germeijs, V., \& Verschueren, K. 2009. Adolescents' career decision-making process: related to quality of attachment to parents? Journal of Research on Adolescence, 19(3), 459-483.

Jacobs, A. 2011. Life Orientation as experienced by learners: a qualitative study in North-West province. South African Journal of Education, 31, 212-223.

Jonck, P. 2014. Validation of a measuring instrument to ascertain the effectiveness of career guidance provided as part of the subject Life Orientation. Academic Journal of Interdisciplinary Studies, 3(6), 359-367.

Leedy, P.D., \& Ormrod, J.E. 2001. Practical research: planning and design. Columbus, OH: Merril Prentice Hall.

Leung, S. A. 2008. The big five career theories. In International handbook of career guidance. Springer Netherlands.

Lindley, L. D. 2005. Perceived barriers to career development in the context of social cognitive career theory. Journal of Career Assessment, 13(3), 271-287.

Magano, M. D. 2011. The new kind of a teacher, to handle the new subject Life Orientation, in a township High School in South Africa. Journal of social sciences, 28(2), 119-127.

Maree, J. G., \& Beck, G. 2004. Using various approaches in career counselling for traditionally disadvantaged (and other) learners: some limitations of a new frontier. South African Journal of Education, 24(1),

Maree, K. (Ed.). 2007. Shaping the story: A guide to facilitating narrative counselling. Pretoria, South Africa: Van Schaik.

Maree, K., \& Molepo, M. 2006. The use of narratives in cross cultural career counselling. In M. McMahon, \& W. Patton (Eds), Career counselling: Constructivist approaches (pp. 69-81). London: Routledge.

McMahon, M., \& Watson, M. (2009). Career psychology research challenges: a systems theory response. South African Journal of Psychology, 39(2), 184-194.

Mills, L. R. 2009. Applying social cognitive career theory to college science majors. (Masters Dissertation). Iowa State University, lowa.

Mittendorf, K., den Brok, P., \& Beijaard, D. 2010. Career conversations in vocational schools. British Journal of Guidance and Counselling, 38(2), 143-165.

Perry, J. C., Dauwalder, J. P., \& Bonnett, H. R. 2009. Verifying the efficacy of vocational guidance programs: Procedures, problems, and potential directions. The Career Development Quarterly, 57(4), 348-357.

Prinsloo, E. 2007. Implementation of life orientation programmes in the new curriculum in South African schools: perceptions of principals and life orientation teachers. South African Journal of Education, 27(1), 155-170. http://www.sajournalofeducation.co. za/index.php/saje

Rooth, E. 2005. An investigation of the status and practice of Life Orientation in South African schools in two provinces (Doctoral Thesis). University of the Western Cape, South Africa.

Salkind, N.J. 2011. Exploring research (8th ed.). Upper Saddle River, New Jersey: Pearson Education, Inc.

Stead, G.B., \& Watson, M.B. (Eds). 2010. Career Psychology: In the South African context. Pretoria: Van Schaik Publishers.

Tang, M., Pan, W., \& Newmeyer, M.D. 2008. Factors influencing high school students' career aspirations. American School Counsellor Association, 11(5), 285-295.

Turner, S., \& Lapan, R.T. 2002. Career self-efficacy and perception of parent support in adolescents career development. Career Development Quarterly, 51, 44-55.

Van der Venter, A.M. 2006. Grade nine learners' experiences of career counselling at school. (Masters Dissertation), University of South Africa, Pretoria. 